\title{
Sparganosis pada Ular Jali (Ptyas korros)
}

\section{Sparganosis in Indo-Chinese Rat Snake (Ptyas korros)}

\author{
Eunike Melanda Fransiska ${ }^{1 *}$, Iwan Sahrial Hamid ${ }^{2}$, Aditya Yudhana ${ }^{3}$, Nusdianto \\ Triakoso $^{4}$, Ratih Novita Praja ${ }^{5}$, Faisal Fikri ${ }^{2}$ \\ ${ }^{1}$ Pendidikan Profesi Dokter Hewan, ${ }^{2}$ Departemen Kedokteran Dasar, ${ }^{3}$ Departemen Parasitologi, ${ }^{4}$ Departemen \\ Klinik, ${ }^{5}$ Departemen Mikrobiologi, Fakultas Kedokteran Hewan PSDKU Banyuwangi, Universitas Airlangga, \\ J1. Wijaya Kusuma No.113, Mojopanggung, Giri, Banyuwangi \\ *Corresponding author: eunikemelandaa@gmail.com
}

\begin{abstract}
Abstrak
Ular Ptyas korros atau ular jali merupakan salah jenis ular yang ada di Indonesia.. Berbagai penyebab kepunahan adalah salah satunya masalah kesehatan seperti penyakit yang disebabkan parasit. Laporan kasus ini bertujuan untuk mengidentifikasi cacing yang ditemukan pada ular $P$. korros yang telah mati, metode identifikasi menggunaka pewarnaan carmine dan diamati dibawah mikroskop dengan perbesaran 40x dan 100x. Hasil identifikasi ditemukan cacing pita Spirometra sp. sebanyak 18 ekor di daerah subkutan dan muskulus sepanjang tubuh ular. Cacing Spirometra sp. menyebabkan penyakit spargonosis yang bersifat zoonosis atau dapat menular pada manusia.
\end{abstract}

Kata kunci: Sparganosis, Ptyas korros, Spirometra sp.

\begin{abstract}
Ptyas korros or Indo-Chinesse Rat snake are one type of snake in Indonesia. Various causes of extinction are health problems such as diseases caused by parasites. This case report aimed to identify worms found in dead P. korros snakes, identification methods using carmine staining and observed under a microscope with a magnification of $40 x$ and 100x. Identification results were found as many as 18 Spirometra sp. tapeworms in the subcutaneous and muscular areas along the snake's body. Spirometra sp. worm causes spargonosis which is zoonotic or can be transmitted to humans.
\end{abstract}

Keywords: Sparganosis, Ptyas korros, Spirometra sp.

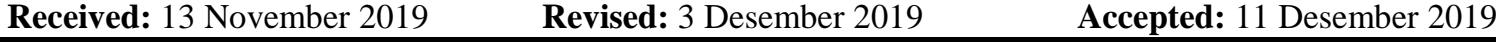

\section{PENDAHULUAN}

Ptyas korros (Indochinese Rat Snake) atau di Indonesia disebut ular jali merupakan jenis ular yang tidak berbisa (non-venomous) yang dapat ditemukan di Sumatra, Jawa, dan Kalimantan (Kurniawan dkk., 2018; Auliya et al., 2002). Ular merupakan satwa memiliki kepentingan bagi manusia dan dalam menjaga stabilitas ekosistem, sehingga pelestarian ular harus dijaga (Wicaksono dkk., 2015). Berbagai ancaman kepunahan populasi tidak hanya dari lingkungan tetapi juga peningkatan masalah kesehatan seperti penyakit parasit dari infeksi cacing pita (Soehir et al., 2015). Sparganosis adalah penyakit yang disebabkan cacing pita Spirometra $s p$. yang mampu menginfeksi ular karena menelan larva infektif yaitu plerocercoid (spargana) dan bersifat zoonosis atau mampu menular pada manusia (Zhou et al., 2008). Sparganosis telah dilaporkan di 39 negara didunia seperti Asia Timur, Asia Tenggara, Eropa, Amerika, Afrika, dan Australia (Wang et al., 2014). Kejadian sparganosis di Indonesia dilaporkan pada ular Dendrelapis pictus dengan prevalensi $50.85 \%$ dan pada ular P. mucosus dengan angka prevalensi 68\% (Yudhana et al., 2019; Pranashinta et al., 2017). Menurut hasil penelitian Wang et al. (2011) beberapa spesies ular di Cina terinfeksi cacing Spirometra erinaceieuropaei salah satunya adalah ular $P$. korros. 
Laporan kasus Spirometra pada ular $P$. korros belum pernah terlaporkan di Indonesia, sehingga tujuan dari laporan kasus ini adalah untuk menambah wawasan serta informasi mengenai kejadian sparganosis dan mengidentifikasi morfologi cacing pita Spirometra sp. pada ular $P$. korros serta dapat menjadi acuan diagnosa dan pengendalian penyakit sparganosis yang bisa di aplikasikan oleh dokter hewan praktisi maupun peniliti.

\section{METODE}

Satu ekor ular P. korros dengan panjang 50 $\mathrm{cm}$ didapatkan dari pemilik hewan di wilayah kota Banyuwangi yang telah mati dibawa ke Laboratorium Biologi Anatomi PSDKU Universitas Airlangga. Tubuh ular terdapat nodul tampak dari luar yang diduga nodul tersebut disebabkan oleh infeksi cacing pada bagian subkutan, untuk memastikan ular perlu dinekropsi. Ular dinekropsi dengan melepaskan kulit dari leher hingga ekor dan memeriksa nodul hingga ke organ dalam. Cacing yang ditemukan dalam tubuh ular P. korros disimpan ke dalam larutan alkohol gliserin 5\% dan akan diidentifikasi menggunakan metode pewarnaan carmine (Kuhlman, 2006) diperiksa menggunakan mikroskop dengan perbesaran 40x dan 100x.

\section{HASIL DAN PEMBAHASAN}

Bedasarkan hasil nekropsi ular P. korros ditemukan cacing pipih, panjang dan berwarna putih dengan tubuh bersegmen sebanyak 18 ekor disepanjang subkutan dan muskulus tubuh ular. Cacing diidentifikasi dengan pewarnaan carmine dan diamati dengan mikroskop perbesaran 40x dan 100x. Hasil identifikasi menunjukkan scolex dengan dua lekukan penghisap dan tubuh yang terdiri dari beberapa segmen, dari morfologi tersebut cacing diidentifikasi sebagai larva infektif yaitu plerocercoid (spargana) cacing Spirometra sp. Panjang rata-rata larva adalah \pm 3 $5 \mathrm{~cm}$ dan lebar $\pm 0.2-0.3 \mathrm{~cm}$.

Larva infektif Spirometra sp. menyebabkan sparganosis pada ular, dan jenis reptil lainnya serta mamalia seperti babi bahkan manusia. Ular yang terinfeksi Spirometra sp. biasanya karena mengkonsumsi katak yang terinfeksi stadium infektif plerocercoid. Spirometra $s p$. pada siklus hidupnya memiliki tiga host yang berbeda, host perantara pertama adalah krustacea (Cyclops), host perantara kedua adalah kecebong atau katak, host utama Spirometra sp. adalah anjing atau kucing, ular dapat menjadi host perantara kedua atau dapat juga menjadi host paratenik (Yin et al., 2006).

Spirometra sp. berkembang menjadi dewasa di dalam usus halus anjing atau kucing dan akan menghasilkan telur yang keluar bersama feses anjing atau kucing di lingkungan sampai menjadi telur berembrio dan akan pecah di air menjadi coracidium. Stadium coracidium tersebut ketika termakan oleh krustacea akan berkembang menjadi stadium procercoid. Krustacea yang terinfeksi jika termakan oleh katak atau kecebong sebagai host perantara kedua maka akan berkembang menjadi stadium plerocercoid (Lescano et al., 2013).

Sparganosis juga dapat menginfeksi manusia karena memakan daging katak atau ular yang terinfeksi plerocercoid dalam kondisi mentah atau setengah matang, serta kebiasaan masyarakat untuk tidak mencuci tangan secara benar setelah mengolah bahan dari katak atau ular juga dapat menjadi sarana terinfeksi plerocercoid (Li et al., 2011).

Sparganosis pada manusia terlaporkan diseluruh dunia, tetapi sebagian besar terjadi pada negara di Asia Timur dan Tenggara (Kim et al., 2018). Negara-negara Asia Timur seperti Cina, Korea, Jepang, Thailand memiliki angka prevalensi lebih tinggi, disebabkan karena masyrakat mayoritas mempunyai kebiasaan memakan daging ular dan katak mentah, serta menelan empedu ular. Metode memasak ular yang kurang tepat juga akan meningkatkan resiko terinfeksi sparganosis pada manusia (Chen et al., 2012). Indonesia juga pernah terlaporkan kasus sparganosis pada manusia di Ambon, Indonesia Timur (Margono et al., 2008). Gejala klinis pada manusia tergantung lokasi setelah menelan larva infektif (Lescano et al., 2013). 


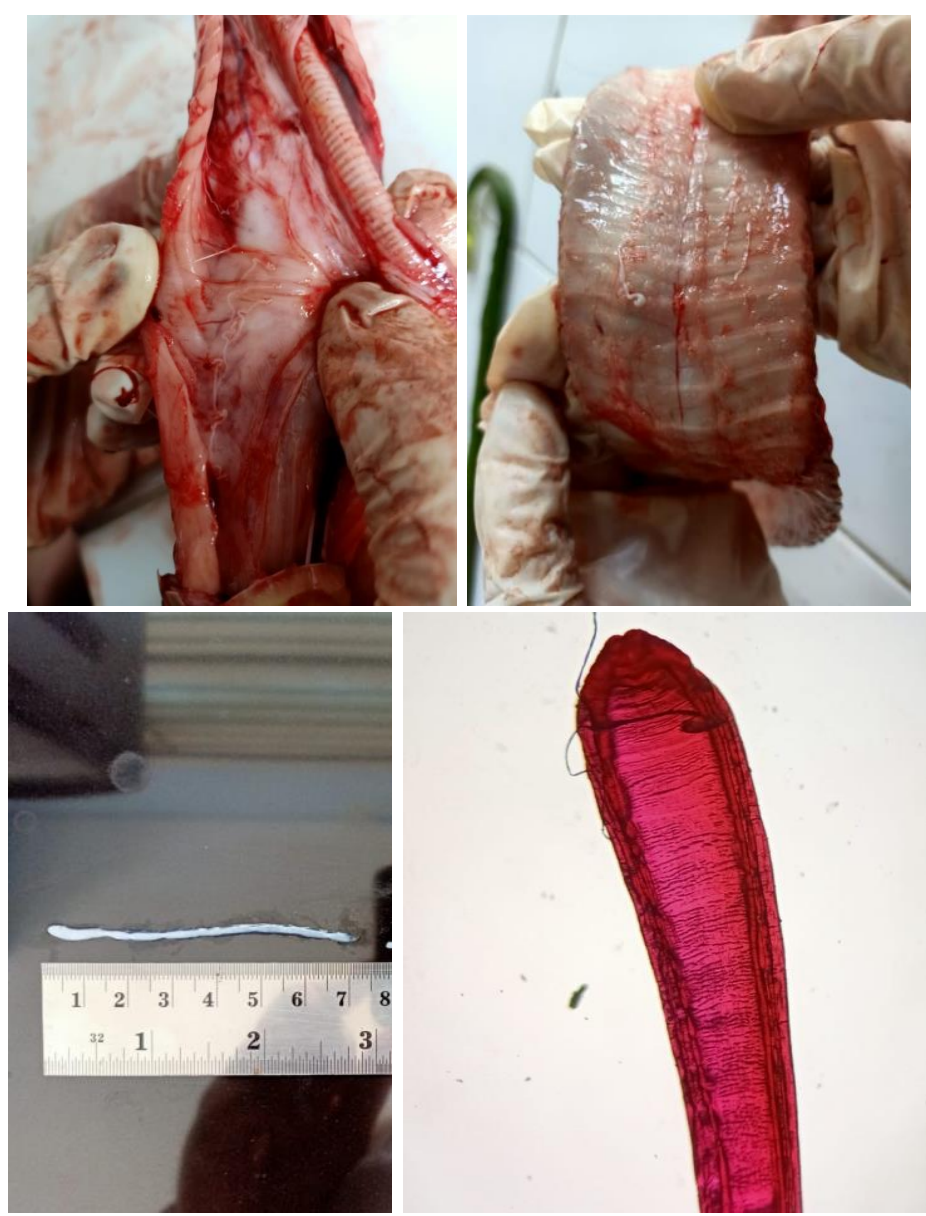

Gambar 1. (A) Spirometra sp. pada P. korros; (B) Spirometra sp. pada subkutan; (C) Makroskopis Spirometra sp.; (D) Mikroskopis Spirometra sp.

Larva Spirometra $s p$. menyerang pada mata, sistem saraf pusat, payudara, paru - paru, epididimis, kandung kemih, jantung, ginjal, telinga, jaringan subkutan, tulang, bahkan otak (Sucahyono dkk., 2018).

Gejala klinis yang muncul pada ular adalah massa pada subkutan atau nodul serta dermatitis atau septikemia, abrasi, ulcer, dan luka pada kulit ular. Anemia, peradangan kronis, malnutrisi, ulcerasi gastrointestinal, dan disfungsi ginjal merupakan gejala lain yang timbul akibat sparganosis pada ular (Mader, 2005). Terapi untuk penyakit sparganosis adalah pemberian obat Praziquantel secara peroral selama 100 hari hingga hewan terbebas dari telur spirometra (Linda et al.,2014). Terapi yang lain dapat di gunakan adalah tindakan operatif dengan cara pengambilan larva atau cacing Spirometra sp. (Botterel et al., 2003).

\section{KESIMPULAN}

Ditemukan cacing Spirometra sp. pada ular P. korros yang telah mati. Morfologi cacing secara makroskopis memiliki panjang rata-rata 3-5 $\mathrm{cm}$ bewarna putih dan berbentuk pipih. Spirometra sp. ditemukan sepanjang tubuh ular pada muskulus dan subkutan. Sparganosis pada ular $P$. korros merupakan laporan kasus pertama di Indonesia. Penemuan sparganosis pada ular $P$. korros menjadi peringatan kepada masyarakat terhadap penyakit zoonosis.

\section{UCAPAN TERIMA KASIH}

Peneliti mengucapkan terimakasih kepada Universitas Airlangga PSDKU di Banyuwangi atas dukungan fasilitas sehingga laporan kasus ini dapat terselesaikan. Peneliti juga mengucapkan terimakasih kepada tim asisten dosen parasitologi veteriner yang telah 
bekerjasama sehingga seluruh kegiatan dapat dilaksanakan dengan baik.

\section{DAFTAR PUSTAKA}

Auliya, M. 2002. Rediscovery of the Indochinese rat snake Ptyas korros (Schlegel, 1837) (Serpentes: Colubridae) in Borneo. Raffles Bul. Zool., 50(1), 197-198.

Botterel, F., Bou' e, P. 1930. Ocular Sparganosis: A Case Report. J. Travel Med., 10(4), 245246.

Chen, X.H. 2012. A case report of bronchial Sparganosis mansoni and literature review. Thesis. Guangxi Medical University, Guangxi, China.

Kuhlmann, W.F. 2006. Preservation, Staining, and Mounting Parasite Speciment

Kurniawan, N., Abdillah, M.F., Nugraha, F.A.D. 2018. Unusual p-distance value among rat snake group (Ptyas: Colubridae) in Sumatra and Java). AIP Publishing, 1(1), 060012.

Lescano, A.G., Zunt, J. 2013. Other Cestodes: Sparganosis, Coenurosis, and Taenia crassiceps cysticercosis. In: Aminoff, M. J., Boller, F. and Swaab, D. F. (Eds), Handbook of Clinical Neurology, Amsterdam: Elsevier. pp: 335-345.

Li, M.W., Song, H.Q., Li, C., Lin, H.Y., Xie, W.T., Lin, R.Q., Zhu, X.Q. 2011. Sparganosis in mainland China. Int. J. Infect. Dis., 15(3), 154-156.

Linda, S., Jennifer, K., Rebecca, H., Gilda, R., Wencke. 2014. Praziquantel Treatment for Platynosomum species infection of a domestic cat on St Kitts, West Indies. J. Fel. Med. Surg. Open Reports, 1(1), 1-4.

Mader, D.R. 2006. Reptile medicine and surgery. Saunders-Elsevier.
Pranashinta, G.T., Suwanti, L.T., Koesdarto, S., Poetranto, E.D. 2017. Spirometra in Ptyas mucosus Snake in Sidoarjo, Indonesia. KnE Life Sci., 3(6), 34-40.

Soheir, A.H.R., Mohey, E.Z., El-Latif A., Nadia, I.M., Obaida, F.E. 2015. Description of some acanthocephalan species from some reptiles in Qena governorate. J. Pharm. Biol. Sci., 10(2), 31-36.

Sucahyono, S.W., Pratama, M.R.H., Syaikudin, A., Nurdian, Y. 2018. Fraktur Patologi yang Disebabkan oleh Sparganosis.

Wang, F., Li, W., Hua, L., Gong, S., Xiao, J., Hou, F., Yang, G. 2014. Spirometra (Pseudophyllidea, Diphyllobothriidae) severely infecting wild-caught snakes from food markets in Guangzhou and Shenzhen, Guangdong, China: Implications for public health. Sci. World J., 2014(1), 1-6.

Wang, F., Zhou, L., Gong, S., Deng, Y., Zou, J., Wu, J., Liu, W., Hou, F. 2011.Severe infection of wild-caught snakes with Spirometra erinaceieuropaei from food markets in Guangzhou, China involves a risk for zoonotic sparganosis. J. Parasitol., 97(1), 170-172.

Wicaksono, A., Madang, K., Dayat, E. 2015. Identifikasi Jenis-Jenis Ular Di Desa Muktijaya Kecamatan Muara Telang Kabupaten Banyuasin Dan Sumbangannya Pada Pembelajaran Biologi SMA.

Yin, G.R., Yang, Y.B., Li, P.Z. 2006. Common food-borne parasitic diseases and their prevention and control in China. Chin. J. Dis. Contr. Prevent., 10, 400-402.

Yudhana, A., Praja, R.N., Supriyanto, A. 2019. The medical relevance of Spirometra tapeworm infection in Indonesian Bronzeback snakes (Dendrelaphis pictus): A neglected zoonotic disease. Vet. World, 12(6), 845-848. 
Zhou, P., Chen, N., Zhang, R.L., Lin, R.Q., Zhu, X.Q. 2008. Foodborne parasitic zoonoses in
China: Perspective for control. Trends Parasitol., 24(4), 190-196. 